\title{
Revisão do gênero Tomrogersia Fragoso (Coleoptera, Cerambycidae)
}

\author{
Marcela L Monné ${ }^{1} \&$ Miguel A. Monné ${ }^{1,2}$
}

\author{
${ }^{1}$ M useu Nacional, Universidade Federal do Rio de Janeiro. Quinta da Boa Vista, São Cristovão, 20940-040 Rio de Janeiro, \\ Rio de Janeiro, Brasil. \\ ${ }^{2}$ Bolsista do CNPq.
}

\begin{abstract}
Revision of the genus Tomrogersia Fragoso (Coleoptera, Cerambycidae). The genus Tomrogersia is redescribed, $T$. villiersi sp. nov. (Colombia) and the female of $T$. acanthofemorata are described.

KEY WORDS. Acanthocinini; Lamiinae; Neotropical; new species.
\end{abstract}

RESUMO. O gênero Tomrogersia é redescrito, $T$. villiersi sp. nov. (Colômbia) e a fêmea de $T$. acanthofemorata são descritas.

PALAVRAS-CHAVE. Acanthocinini; Lamiinae; Neotropical; espécie nova.

A tribo Acanthocinini compreende 149 gêneros e mais de 950 espécies na Região Neotropical (Monné 2005). Fragoso (1980) descreveu Tomrogersia, na tribo Desmiphorini, para T. acanthofemorata com base em um exemplar macho. Monné (1995) situou o gênero em Acanthocinini. Neste trabalho, o gênero é redescrito e são descritas a fêmea de $T$. acanth ofemorata e uma nova espécie, T. villiersi sp. nov., da Colômbia.

O material examinado pertence ao Muséum National d'Histoire Naturelle, Paris (MNHN) e ao Museu Nacional, Universidade Federal do Rio de Janeiro, Rio de Janeiro (MNRJ).

\section{Tomrogersia Fragoso, 1980}

Tomrogersia Fragoso, 1980: 473; Monné, 2005: 136.

Espécie-tipo: Tomrogersia acanthofemorata por designação original.

Cabeça subvertical, fronte transversa e intumescida; vértex ligeiramente deprimido. OIhos grosseiramentefacetados, fortemente emarginados. Genas triangulares e curtas. Labro e anteclípeo convexos. Mandíbulas com borda externa carenada, ápice bífido. Pal pos maxilares mais Iongos que os labiais; segmento basal cerca da metade do comprimento do seguinte; 24 subiguais em comprimento; segundo e terceiro cônicos; o apical acuminado. Lábio com mento trapezoidal; palpos labiais com inserções próximas entre si; segmento basal cerca de $1 /$ 3 do comprimento do seguinte; 2-3 subiguais; segundo cônico; o apical acuminado. Antenas filiformes; escapo longo, gradualmente engrossado para o ápice; pedicelo curto e transverso.

Protórax transverso, a cada lado com um tubérculo pósmediano aguçado. Pronoto com pontos grossos e rasos na margem posterior. Cavidades coxais anteriores arredondadas, fechadas atrás. Processo prosternal distintamente estreitado na região mediana. Mesosterno plano. Processo mesosternal cerca de $1 / 3$ do diâmetro da cavidade mesocoxal. Cavidades mesocoxais abertas aos lados. Sulco metasternal alcança o terço basal do metas- terno. Escutelo curto, margem apical arredondada. Élitros aplanados, cerca de quatro a cinco vezes o comprimento do protórax e, nos 2/3 basais, com pontos grossos, moderadamente densos e rasos. Úmeros arredondados e ligeiramente projetados anteriormente.

Profêmures, nos machos, distintamente dilatados, mais desenvolvidos que os demais e com espinho externo ventral, pós-mediano; nas fêmeas, clavados e sem espinho; meso- e metafêmures subclavados. Tíbias cilíndricas, delgadas, tão longas quanto os fêmures. Mesotíbias sulcadas no terço apical interno. Esporões tibiais curtos, delgados, o externo ligeiramente mais longo. Escovas tarsais compactas.

Urosternito I cerca de 1/3 mais Iongo que o seguinte; II$\checkmark$ subiguais em comprimento; $V$ gradual mente estreitado para o ápice e este com a margem emarginada.

Discussão. Entre os gêneros de Acanthocinini, Tomrogersia aproxima-se de Neseuterpia Villiers, 1980 pelo protórax com tubércul os laterais pós-medianos, o pronoto sem tubérculos e com pontos grossos na margem posterior e pelos élitros com pontos grossos nos 2/3 basais e sem crista, tufo ou carena lateral. Tomrogersia difere, principalmente, de Neseuterpia pelos ol hos grosseiramentefacetados, os profêmures, nos machos, são distintamente dilatados e com espinho ventral pós-mediano e o esternito $\mathrm{V}$ gradualmente estreitado para o ápice. Em Neseuterpia os olhos são finamente facetados, os fêmures são clavados e sem dimorfismo e o esternito $V$ é distintamente acuminado para o ápice (VILLIERS 1980: 88, figs 3, 4).

\section{Tomrogersia acanthofemorata Fragoso, 1980}

Figs 1-2

Tomrogersia acanthofemorata Fragoso, 1980: 743; Monné, 2005: 136.

Macho. Tegumento de maneira geral avermel hado exceto ápice dos antenômeros III-XI e três manchas nos élitros (Fig. 

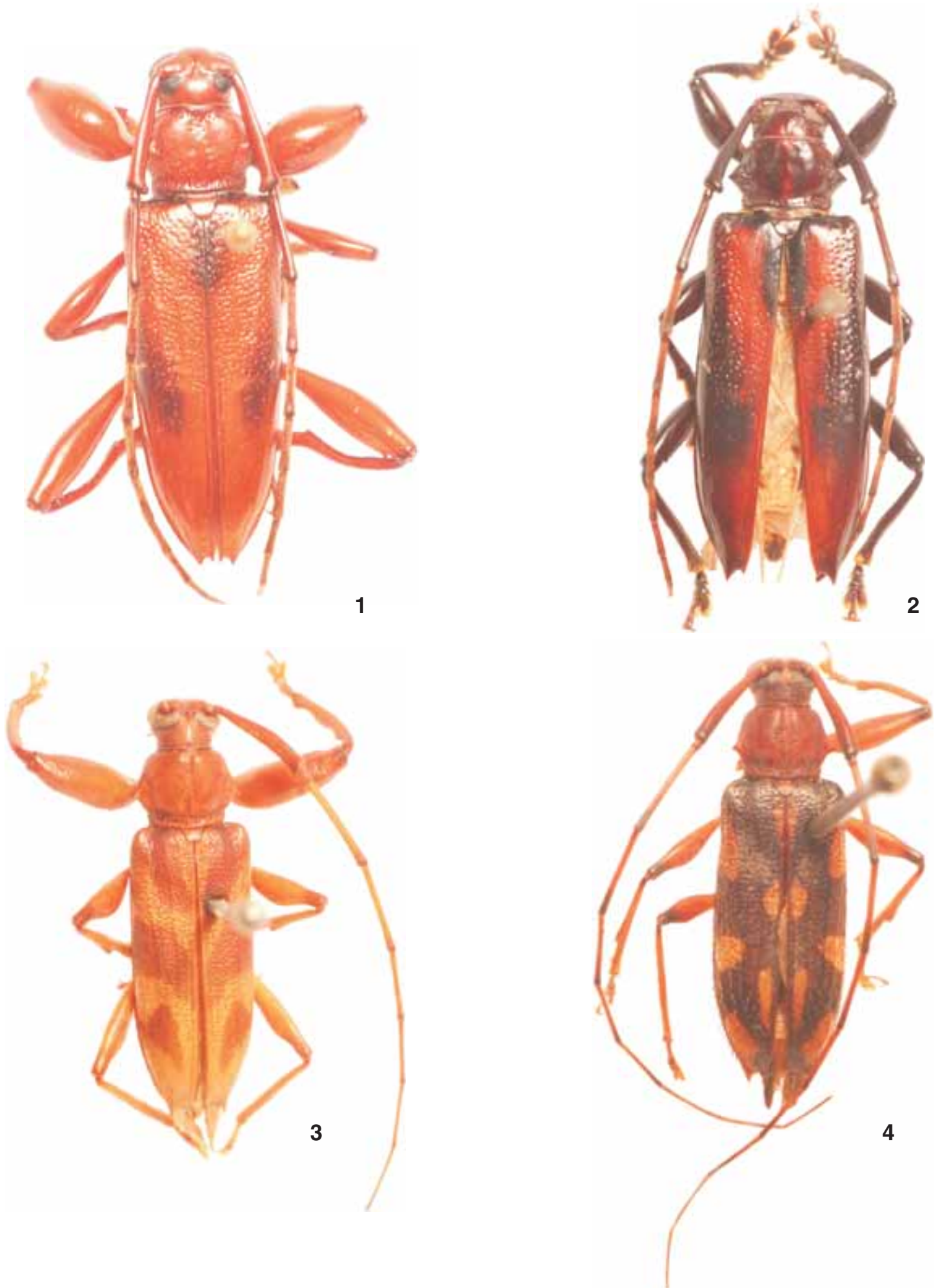

Figuras 1-4. (1-2) Tomrogersia acanthofemorata: (1) holótipo macho, 23,2 mm; (2) fêmea, 20,5 mm; (3-4) T. villiersi sp. nov.: (3) parátipo macho, 13,8 mm; (4) holótipo fêmea, 11,8 mm. 
1), uma mediana após o escutelo e duas oblíquas após o meio, enegrecidos. Corpo, de maneira geral, glabro e brilhante.

Lobos oculares superiores tão distantes entre si quanto 1,5 vezes a largura de um lobo. Antenas ultrapassam os ápices elitrais no antenômero IX; ápice interno do escapo com projeção arredondada; antenômeros III-XI encurtados para o ápice e com pubescência dourada.

Processo mesosternal entalhado na extremidade. Élitros glabros; ápices com projeção espiniforme nos ângulos sutural e lateral.

Pernas posteriores cerca de um terço mais longas que as anteriores. Procoxas e mesocoxas deprimidas. Protrocanter (Fragoso 1980: 745, fig. 2) projetado anteriormente, com encaixe no ápice interno da tíbia; meso- e metatrocanter sem projeção. Profêmures globosos e com espinho interno e ventral; meso- e metafêmures com espinho interno pré-apical. Protíbias arqueadas e com dois espinhos desenvolvidos, pré-apicais; metatíbias arqueadas e com projeção interna pré-apical. Metatarsômero I com comprimento subigual ao II.

Fêmea (Fig. 2). Tegumento vermelho-escuro a preto; antenômeros III-XI vermelho-escuros com ápices pretos; élitros pretos com faixa irregular mediana, Iongitudinal, vermelha. Antenas ultrapassam os ápices elitrais no antenômero X. Pernas, de maneira geral, menos desenvolvidas que nos machos; trocanteres sem projeção; meso- e metafêmures apenas com projeção romba pré-apical; tíbias lineares e sem espinhos.

Dimensões, em milímetros, macho/fêmea. Comprimento total, 23,2/20,5; comprimento do protórax, 3,4/2,8; maior largura do protórax (sem tubérculos), 4,1/3,2; comprimento do élitro, 16,3/15,8; Iargura umeral, 6,5/5,9.

Material examinado. ColômBia, Valle del Cauca: Iower Anchicaya alt. $400 \mathrm{~m}$, "tropical very wet forest netted by R. Wilkerson", 11-VI-1975, holótipo macho (ex-coleção Fragoso) (MNRJ). Equador, Pichincha: Puerto Quito, fêmea, I.1985, F. Cuesta leg. (MNRJ).

\section{Tomrogersia villiersi sp. nov. Figs 3-4}

Etimologia. Homenagem póstuma à AndréVilliers, MNHN.

Macho. Tegumento de maneira geral castanho-alaranjado a avermelhado; antenômeros III-XI castanhos, com ápices concolores ou enegrecidos; élitros (Fig. 3) castanho-claros exceto três manchas irregulares, em cada élitro, castanho-escuras. Corpo recoberto por fina pubescência esbranquiçada pouco aparente.

Lobos oculares superiores tão distantes entre si quanto à largura de um lobo. Antenas ultrapassam os ápices elitrais no antenômero VI ou VII; escapo sem projeção apical; face ventral do escapo, pedicelo e antenômeros III-IV com cerdas curtas e pretas; III-XI gradualmente decrescentes em comprimento.

Pronoto com pontos moderadamente grossos e rasos na região mediana longitudinal. Processo mesosternal truncado na extremidade.
Élitros com cerdas eretas, esparsas e pretas; ápices com espinho lateral. Pernas posteriores ligei ramente mais curtas que as anteriores. Procoxas e mesocoxas globosas. Trocanteres sem projeção. Profêmures com grânulos densos na metade apical. Tíbias lineares; protíbias ligeiramente engrossadas no ápice, carenadas na face ventral e com a margem irregular e granulada. Metatarsômero I 1,5 vezes mais longo que o II.

Fêmea (Fig. 4). Tegumento castanho-avermelhado; ápice dos antenômeros, dos fêmures, base das tíbias e dos tarsos, pretos; élitros castanho-escuros ou pretos, cada um com seis manchas alaranjadas irregulares, três pequenas ao longo da sutura e três laterais um pouco maiores sendo que a posterior al cança a epipleura. Pernas, de maneira geral, menos desenvolvidas que nos machos e sem grânulos, espinhos ou carenas.

Dimensões, em milímetros, macho/fêmea. Comprimento total, 13,8-12,5/11,8; comprimento do protórax, 2,2-2,0/1,8; maior largura do protórax (sem tubérculos), 2,9-2,4/2,0; comprimento do élitro, 9,8-8,2/8,0; largura umeral, 3,8-3,4/2,9.

Material-tipo. Holótipo fêmea, ColômBIA, Valle del Cauca: Dagua, Escalarete Palma, 24.V.1990, L. C. Pardo col. (MNRJ). Parátipos: fêmea, mesmos dados do holótipo (MNRJ); Valle del Cauca: Calima, El Tagual, macho, 11.IX.1982, L.C. Pardo leg. (MNRJ); Rio Dagua, macho, W. Rosenberg leg. (MNHN).

Discussão. Tomrogersia villiersi difere deT. acanthofemorata por apresentar as antenas mais longas em ambos os sexos, ultrapassando os ápices elitrais nos antenômeros VI ou VII, o processo mesosternal truncado na extremidade, os élitros com cerdas e as pro- e mesocoxas globosas. Em T. acanthofemorata os antenômeros III-XI são distintamente decrescentes em comprimento e alcançam os ápices elitrais nos antenômeros IX ou $X$, o processo mesosternal é ental hado na extremidade, os élitros são glabros e as pro- e mesocoxas são deprimidas.

\section{AGRADECIMENTOS}

A José R.M. Mermudes (UERJ) pelas execução das fotos.

\section{REFERÊNCIAS BIBLIOGRÁFICAS}

Fragoso, S.A. 1980. Tomrogersia acanthofemorata, n. gen., sp. nov. (Coleoptera, Cerambycidae). Revista Brasileira de Biologia, Rio de Janeiro, 40 (4): 743-746.

Monné, M.A. 1995. Catalogue of the Cerambycidae (Coleoptera) of the Western Hemisphere. Part XVIII. Subfamily Lamiinae: Tribe Acanthocinini. São Paulo, Sociedade Brasileira de Entomologia, 196p.

Monné, M.A. 2005. Catal ogue of the Cerambycidae (Coleoptera) of the Neotropical Region. Part II. Subfamily Lamiinae. Zootaxa, Auckland, 1023: 1-759.

VILLIERS, A. 1980. Coléoptères Cerambycidae des Petites Antilles. Nouveaux genres, nouvelles espèces. Désignation de types (Troisième note). Revue Française d'Entomologie, N.S., Paris, 2 (2): 86-98.

Recebido em 02.VIII.2006; aceito em 17.XI.2006. 